\title{
Cardiac Surgery in Jehovah's Witness Patients: Experience of a Brazilian Tertiary Hospital
}

Felipe Homem Valle1, MD, ScD; Fernando Pivatto Júnior², MD; Bruna Sessim Gomes ${ }^{1}, M D ;$ Tanara Martins de Freitas ${ }^{1}, \mathrm{MD}$; Vanessa Giaretta' ${ }^{1}$ MD; Miguel Gus ${ }^{1}, \mathrm{MD}, \mathrm{MSc}$, ScD

DOI: 10.21470/1678-9741-2017-0012

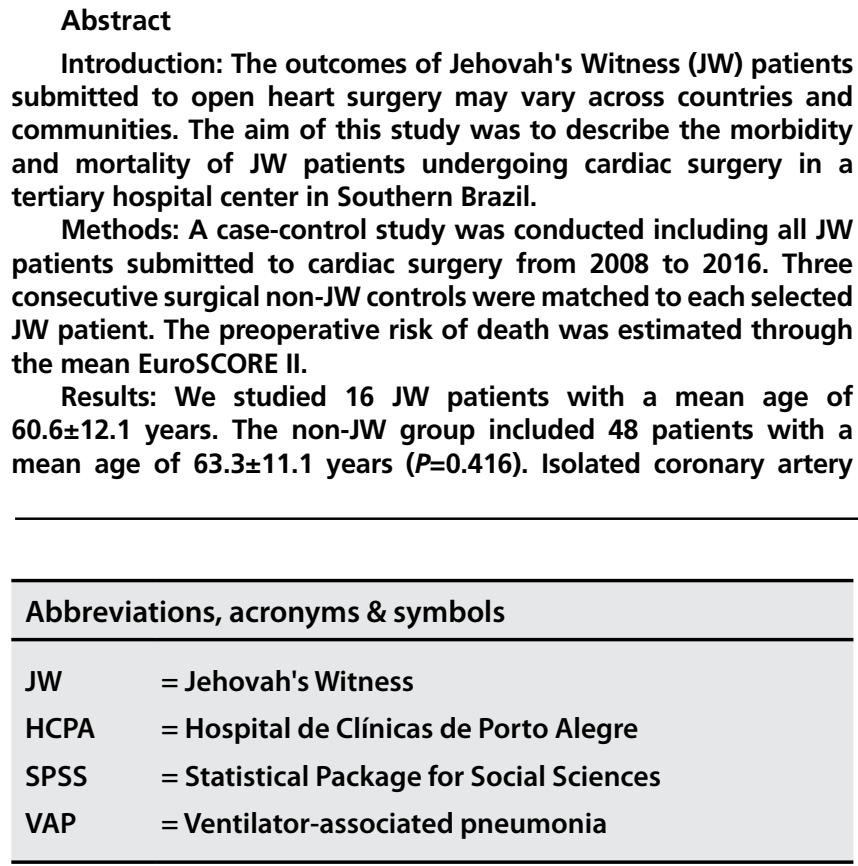

\section{INTRODUCTION}

Based on religious beliefs, Jehovah's Witness (JW) refuse blood products transfusions. In some clinical situations, it may be both, a healthcare and an ethical challenge. Despite the development in surgical techniques, more than $50 \%$ of patients receive perioperative transfusion in cardiac surgeries ${ }^{[1]}$.

More recently, the data of case series ${ }^{[2-6]}$ and some controlled studies $^{[7-10]}$ showed that the perioperative and postoperative prognosis of JW is similar to those of patients who do not have bypass graft surgery was the most frequent surgery performed in both groups. Median EuroSCORE II was 1.29 (IQR: 0.66-3.08) and 1.43 (IQR: $0.72-2.63)$, respectively $(P=0.988)$. The mortality tended to be higher in JW patients ( $18.8 \%$ vs. $4.2 \%, P=0.095)$, and there was a higher difference between the predicted and observed mortality in JW patients compared with controls (4.1 and $18.8 \%$ vs. 2.1 and $4.2 \%)$. More JW patients needed hemodialysis in the postoperative period (20.0 vs. $2.1 \%, P=0.039$ ).

Conclusion: We showed a high rate of in-hospital mortality in JW patients submitted to cardiac surgery. The EuroSCORE II may underestimate the surgical risk in these patients.

Keywords: Jehovah's Witnesses. Cardiac Surgical Procedures. Mortality.

restrictions to blood products transfusions. However, the rates of mortality and postoperative complications in patients that undergo cardiac surgery are variable. Although clinical results are determined largely by sample characteristics and by the preoperative and postoperative care, assistant teams cultural and religious factors may play a specific role in the surgical success of these patients. Therefore, the evaluation of the cardiac surgery results in JW patients should be evaluated in different cultural scenarios.

In Brazil, there are no studies that address local results in cardiovascular procedures in such context. The 2010 Brazilian census $^{[11]}$ showed that $1,393,208$ persons $(0.73 \%$ of whole population) were identified as JW. The aim of this study was to describe the morbidity and mortality of JW patients undergoing cardiac surgery in a tertiary hospital center of Porto Alegre, Southern Brazil, considering only the more contemporary cases. We also compare the predicted mortality estimated by the EuroSCORE I[12] in JW patients and controls.

'Hospital de Clínicas de Porto Alegre (HCPA), Cardiology Division, Porto Alegre, RS, Brazil.

${ }^{2}$ Hospital de Clínicas de Porto Alegre (HCPA), Internal Medicine Division, Porto Alegre, RS, Brazil.

This study was carried out at the Hospital de Clínicas de Porto Alegre (HCPA), Porto Alegre, RS, Brazil.
Correspondence Address: Fernando Pivatto Júnior

Hospital de Clínicas de Porto Alegre (HCPA)

Rua Ramiro Barcelos, 2.350, sala 700 - Porto Alegre, RS, Brazil

Zip code: 90.035-903

E-mail:fpivatto@gmail.com 


\section{METHODS}

The current case-control study was carried out at the Hospital de Clínicas de Porto Alegre (HCPA), a tertiary hospital in Southern Brazil (state of Rio Grande do Sul), during the period from 2008 to 2016. All JW patients submitted to cardiac surgery were selected. The patients' identification as JW occurred through surgical schedules, bioethics consultations and keyword search in the electronic medical records system. Three consecutive surgical non-JW controls were matched to each selected JW patient, including only surgeries with extracorporeal circulation.

Preoperative risk of death was estimated through the mean EuroSCORE $\|^{[12]}$. Death during hospitalization, regardless of its length, was defined as hospital mortality. The registry of at least one of the following complications was considered as hospital morbidity: creatinine $>2 \mathrm{mg} / \mathrm{dL}$, mechanical ventilation $>48$ hours, myocardial infarction, need for either hemodialysis or intra-aortic balloon pump, reintervention due to bleeding, reintubation, stroke and use of antibiotics. Definitions of active endocarditis, chronic pulmonary disease, critical preoperative state, surgery urgency, extracardiac arteriopathy and recent myocardial infarction ( $<90$ days) were the used in the EuroSCORE II study ${ }^{[12]}$. Creatinine clearance was estimated through CockroftGault formula.

Data were collected directly from the patients' electronic charts, and analyzed in the software Statistical Package for Social Sciences (SPSS) 21.0. Qualitative data were reported as absolute and relative frequency; mean ( \pm standard deviation) or median (interquartile range) were used for quantitative variables. The comparison of the groups was performed by Student's t-test for quantitative variables with normal distribution, by MannWhitney $\mathrm{U}$ test, for the quantitative without normal distribution and chi-square test for categorical variables. In situations of low frequency, Fisher exact test was used. Normality of the distribution of each variable was evaluated using Shapiro-Wilk test. The significance level adopted in all tests was 5\%. The present study was submitted and approved by the local Research Ethics Committee.

\section{RESULTS}

During the period under study, 16 JW patients were submitted to cardiac surgery at the institution. The demographic characteristics of the whole sample are described in Table 1. Patients were neither receiving iron supplementation therapy nor were in critical state in the preoperative period.

Isolated coronary artery bypass graft surgery was the most frequent surgery performed in both groups. Extracorporeal circulation and cross-clamp times were similar between JW and non-JW groups. Surgical characteristics data are described in Table 2.

Hospital outcomes are presented in Table 3. There was no statistically significant difference in the rate of mortality or morbidity, with a trend to a higher mortality in the JW group. Causes of death were septic $(n=1)$, cardiogenic $(n=1)$ and hypovolemic $(n=1)$ shock in the JW group; ischemic stroke $(n=1)$ and right ventricle failure/shock $(n=1)$ were responsible for the deaths in the control group. The levels of both hematocrit and hemoglobin at discharge were leveled between the two groups. Lengths of stay, considering both intensive care unit and ward stay after surgery, were also similar between groups.

The comparison of the predicted and observed mortality is shown in Figure 1. As noted, unlike non-JW group, the observed mortality was higher than the rate predicted by mean EuroSCORE II in the JW group.

The need for hemodialysis in the postoperative period was significantly higher in JW patients, but the incidence of the other morbidities analyzed was similar between the patients' groups. Detailed hospital morbidity per outcome is shown in Table 4. The reasons for antibiotic use were septic shock due to central line infection $(n=1)$ and ventilator-associated pneumonia (VAP; $\mathrm{n}=1)$ in JW patients; respiratory tract infection $(n=4)$, urinary tract infection ( $n=2)$, surgical wound infection $(n=2)$, VAP $(n=1)$ and diverticulitis ( $n=1)$ accounted for the use of antibiotics in the non-JW group.

\section{DISCUSSION}

In this case-control study, we reported the hospital outcomes of a non-selected group of JW that were submitted to cardiac surgery in a Brazilian tertiary center between 2008 and 2016. Outcomes and demographic variables were compared with a matched control group as described above. The rates of hospital mortality and morbidity were leveled between JW and controls. However, there was a trend toward higher mortality rate in JW than in controls ( 18.8 vs. 4.2\%, respectively; $P=0.095$ ). In addition, necessity of hemodialysis in the postoperative period was greater in JW than in controls (20.0 vs. $2.1 \%$, respectively; $P=0.039$ ). Moreover, it was observed that, in JW, the mortality rates were higher than predicted by the EuroSCORE II. Hemoglobin levels remained similar between groups, both preoperatively and at discharge.

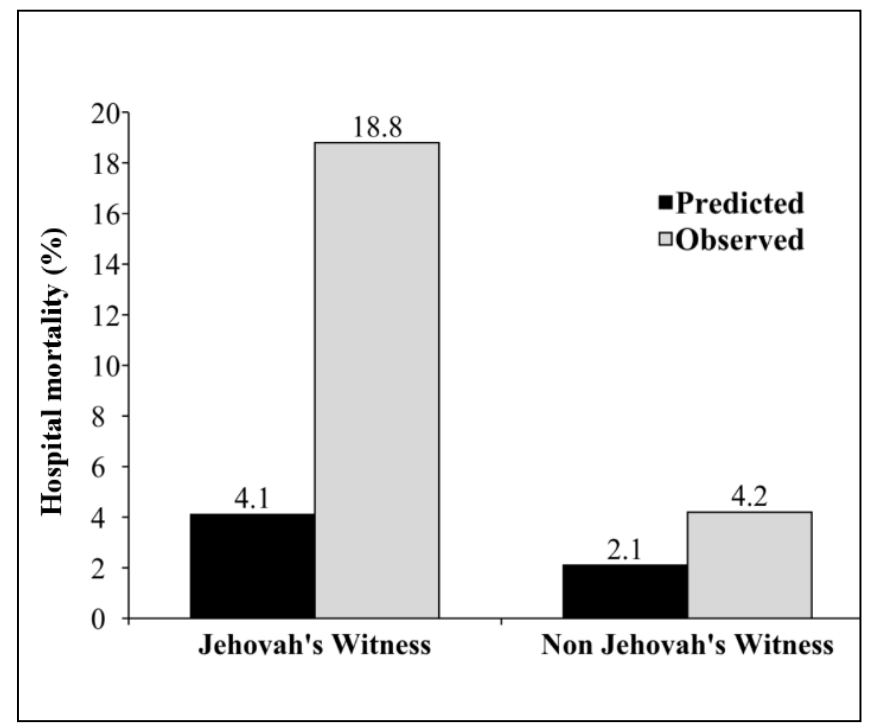

Fig. 1 - Comparison of the predicted and observed hospital mortality in JW and non-JW patients accordingly EuroSCORE II. 
Table 1. Demographic characteristics of the sample.

\begin{tabular}{|c|c|c|c|}
\hline Variable & $J W(n=16)$ & Non-JW $(n=48)$ & $P$ \\
\hline Age & $60.6 \pm 12.1$ & $63.3 \pm 11.1$ & 0.416 \\
\hline Male sex & $9(56.3)$ & $32(66.7)$ & 0.652 \\
\hline Systemic hypertension & $14(87.5)$ & $41(85.4)$ & 1.0 \\
\hline Previous smoking & $6(37.5)$ & $29(60.4)$ & 0.192 \\
\hline Current smoking ( $<30$ days) & - & $5(10.4)$ & 0.319 \\
\hline Chronic pulmonary disease & - & $1(2.1)$ & 1.0 \\
\hline Pulmonary hypertension ( $\geq 31 \mathrm{mmHg}$ ) & $5(31.2)$ & $13(27.1)$ & 0.756 \\
\hline Previous Ml & $5(31.3)$ & $15(31.3)$ & 1.0 \\
\hline Recent Ml & $1(6.3)$ & $10(20.8)$ & 0.265 \\
\hline Diabetes & $4(25.0)$ & $17(35.4)$ & 0.645 \\
\hline Diabetes on insulin & - & $4(8.3)$ & 0.564 \\
\hline NYHA class III/IV heart failure & $3(18.7)$ & $9(18.8)$ & 1.0 \\
\hline LVEF & $56.0(37.5-67.0)$ & $55.5(42.2-68.7)$ & 0.951 \\
\hline CCS class 4 angina & $1(6.3)$ & $8(16.7)$ & 0.430 \\
\hline Unstable angina & - & $1(2.1)$ & 1.0 \\
\hline Previous heart surgery & $1(6.3)$ & $2(4.2)$ & 1.0 \\
\hline Atrial fibrillation & $1(6.3)$ & $6(12.5)$ & 0.669 \\
\hline Extracardiac arteriopathy & $1(6.3)$ & $6(12.5)$ & 0.669 \\
\hline Active endocarditis & $1(6.3)$ & - & 0.250 \\
\hline Creatinine clearance $(\mathrm{mL} / \mathrm{min})^{*}$ & $88.6(50.4-102.3)$ & $72.2(55.1-98.9)$ & 0.617 \\
\hline Preoperative hemodialysis & $1(6.3)$ & - & 0.250 \\
\hline Acetylsalicylic acid use & $6(37.5)$ & $28(58.3)$ & 0.247 \\
\hline Erythropoietin use ${ }^{*}$ & $1(6.7)$ & - & 0.238 \\
\hline Hematocrit (\%) & $39.7(35.2-42.6)$ & $37.4(33.1-41.7)$ & 0.438 \\
\hline Hemoglobin $(\mathrm{g} / \mathrm{dL})$ & $13.6(11.7-14.2)$ & $12.7(11.1-14.2)$ & 0.571 \\
\hline EuroSCORE II & $1.29(0.66-3.08)$ & $1.43(0.72-2.63)$ & 0.988 \\
\hline
\end{tabular}

CCS=Canadian Cardiovascular Society; JW=Jehovah's Witness; LVEF=left ventricular ejection fraction; MI=myocardial infarction;

$\mathrm{NYHA}=$ New York Heart Association

* Excluding a chronic kidney disease on hemodialysis patient.

Data presented as number (\%), mean \pm standard deviation or median (interquartile range).

Previous retrospective studies demonstrated that cardiac surgery might be performed in JW with acceptable outcomes ${ }^{[2-10]}$ Furthermore, retrospective studies that compared mortality and morbidity rates in JWand controls showed leveled results between both groups ${ }^{[7-10]}$. Bhaskar et al. ${ }^{[9]}$ and Pattakos et al. ${ }^{[10]}$ compared outcomes of JW with a control group of transfused patients. Marinakis et al. ${ }^{[7]}$ and Stamou et al. ${ }^{[8]}$ described outcomes of JW with a matched group regardless of blood transfusion. Table 5 shows a comparison of current study with previous retrospective comparative studies. In agreement with previous comparative studies, we observed similar levels of hemoglobin between groups, both preoperatively and at discharge. Our results also showed similar rate of reoperation due to excessive bleeding in JW and in controls. However, the in-hospital mortality rate in JW in our study was higher than in previous studies. In addition, our report is the first to demonstrate both higher necessity of hemodialysis in the postoperative period and a trend toward higher mortality rate in JW than in controls. Notwithstanding, our cohort is the first report that demonstrates higher mortality rates in JW than predicted by the EuroSCORE II in all risk strata.

Our study has several limitations. First, our sample of JW was small. However, this is a non-selected and consecutive cohort 
Table 2. Surgical data.

\begin{tabular}{|c|c|c|c|}
\hline Variable & $\begin{array}{c}J W \\
(n=16)\end{array}$ & $\begin{array}{c}\text { Non-JW } \\
(n=48)\end{array}$ & $P$ \\
\hline Non-elective surgery & $1(6.3)$ & $4(8.3)$ & 1.0 \\
\hline \multicolumn{4}{|l|}{ Surgery } \\
\hline Isolated CABG & $7(43.8)$ & $28(58.3)$ & 0.469 \\
\hline Isolated biological AVR & $3(18.8)$ & $6(12.5)$ & \\
\hline Isolated biological MVR & $2(12.5)$ & $1(2.1)$ & \\
\hline CABG + biological AVR & $1(6.3)$ & $1(2.1)$ & \\
\hline CABG + biological aortic valved graft & $1(6.3)$ & - & \\
\hline Isolated mechanical AVR & $1(6.3)$ & $3(6.3)$ & \\
\hline Mechanical AVR + MVR & $1(6.3)$ & - & \\
\hline Isolated mechanical MVR & - & $2(4.2)$ & \\
\hline Mechanical aortic valved graft + aneurysmectomy & - & $1(2.1)$ & \\
\hline CABG + aorta pseudoaneurysm correction & - & $1(2.1)$ & \\
\hline Mechanical aortic valved graft & - & $1(2.1)$ & \\
\hline Biological aortic valved graft & - & $1(2.1)$ & \\
\hline Heart tumor removal & - & $1(2.1)$ & \\
\hline Interventricular communication correction & - & $1(2.1)$ & \\
\hline Resection of subaortic membrane + septoplasty & - & $1(2.1)$ & \\
\hline Extracorporeal circulation time (minutes) & $58.5(50.7-71.5)$ & $67.5(55.2-90.0)$ & 0.139 \\
\hline Cross-clamp time (minutes) & $38.5(31.2-51.0)$ & $48.0(40.0-65.0)$ & 0.054 \\
\hline
\end{tabular}

AVR=aortic valve replacement; $C A B G=$ coronary artery bypass graft surgery; JW=Jehovah's Witness; MVR=mitral valve replacement Data presented as number (\%) or median (interquartile range).

Table 3. Hospital outcomes.

\begin{tabular}{l|c|c|c}
\hline Outcome & $\begin{array}{c}\text { JW } \\
(\mathbf{n = 1 6 )}\end{array}$ & $\begin{array}{c}\text { Non-JW } \\
(\mathbf{n = 4 8 )}\end{array}$ & $\boldsymbol{P}$ \\
\hline Mortality & $3(18.8)$ & $2(4.2)$ & 0.095 \\
\hline Morbidity & $4(25.0)$ & $14(29.2)$ & 1.0 \\
\hline Last hematocrit (\%) & $28.6(23.6-33.6)$ & $28.8(26.5-32.9)$ & 0.625 \\
\hline Last hemoglobin (g/dL) & $9.2(7.5-11.6)$ & $9.4(8.8-10.9)$ & 0.593 \\
\hline Length of stay (days) & $6.5(6.0-9.5)$ & $7.0(7.0-9.7)$ & 0.143 \\
\hline
\end{tabular}

JW=Jehovah's Witness. Data presented as number (\%) or median (interquartile range).

of JW and there is no record of denial of cardiac surgery to any JW at our hospital. Second, surgical data were heterogeneous between our groups: the rates of combined surgery and valve surgery were higher in JW than in controls. This can partly explain a trend toward higher mortality rate among JW in our cohort. Third, this is a cross-sectional retrospective study with all methodological limitations of such design. Therefore, our results need to be interpreted in a cautious and exploratory fashion.

\section{CONCLUSION}

In conclusion, our study demonstrated a high rate of inhospital mortality in JW and a trend toward higher mortality in JW than in controls. In addition, we observed that in our cohort of JW the mortality risk predicted by EuroSCORE ॥ was not accurate: in fact, EuroSCORE II underestimated surgical risk in JW in our study. To our knowledge, this is the first Brazilian study to compare outcomes of heart surgery in JW with controls. 
Table 4. Hospital morbidity.

\begin{tabular}{|c|c|c|c|}
\hline Hospital morbidity & $\begin{array}{c}J W \\
(n=16)\end{array}$ & $\begin{array}{c}\text { Non-JW } \\
(n=48)\end{array}$ & $P$ \\
\hline Mechanical ventilation > 48h & $4(25.0)$ & $4(8.3)$ & 0.099 \\
\hline Need for hemodialysis* & $3(20.0)$ & $1(2.1)$ & 0.039 \\
\hline Reintubation & $3(18.8)$ & $3(6.3)$ & 0.159 \\
\hline Antibiotic use $^{\dagger}$ & $2(13.3)$ & $10(20.8)$ & 0.714 \\
\hline Creatinine $>2 \mathrm{mg} / \mathrm{dL}^{*}$ & $1(6.7)$ & $4(8.3)$ & 1.0 \\
\hline Perioperative Ml & $1(6.3)$ & $2(4.2)$ & 1.0 \\
\hline Need for IABP & $1(6.3)$ & - & 0.250 \\
\hline Reintervention for bleeding & $1(6.3)$ & $3(6.3)$ & 1.0 \\
\hline Stroke & - & $2(4.2)$ & 1.0 \\
\hline
\end{tabular}

JW=Jehovah's Witness; IABP=intra-aortic balloon pump; MI=myocardial infarction

* Excluding a chronic kidney disease on hemodialysis patient.

${ }^{\dagger}$ Excluding an active endocarditis patient.

Data presented as number (\%).

Table 5. Comparison of current study with previous retrospective comparative studies.

\begin{tabular}{l|c|c|c|c|c}
\hline Variable & $\begin{array}{c}\text { Valle et al. } \\
\text { (current study) }\end{array}$ & Marinakis et al. ${ }^{[7]}$ & Stamou et al. ${ }^{[8]}$ & Bhaskar et al. ${ }^{[9]}$ & Pattakos et al. ${ }^{[10]}$ \\
\hline $\mathrm{n}$ & 16 & 31 & 49 & 49 & 322 \\
\hline Age & $60.6 \pm 12.1$ & $62 \pm 15$ & $62.7 \pm 9.5$ & $65.3 \pm 10.1$ & $62 \pm 13$ \\
\hline Isolated CABG & $7(43.8)$ & $15(48.4)$ & $38(77.5)$ & $25(51.0)$ & $209(64.9)$ \\
\hline Hospital mortality & $3(18.8)$ & $1(3.2)$ & $3(6.1)$ & $1(2.0)$ & $10(3.1)$ \\
\hline
\end{tabular}

$\mathrm{CABG}=$ coronary artery bypass graft surgery

Data presented as number (\%) or mean \pm standard deviation.

\section{Authors' roles \& responsibilities}

FHV Substantial contributions to the conception or design of the work; or the acquisition, analysis, or interpretation of data for the work; drafting the work or revising it critically for important intellectual content; final approval of the version to be published

FPJ Substantial contributions to the conception or design of the work; or the acquisition, analysis, or interpretation of data for the work; drafting the work or revising it critically for important intellectual content; final approval of the version to be published

BSG Substantial contributions to the conception or design of the work; or the acquisition, analysis, or interpretation of data for the work; final approval of the version to be published

TMF Substantial contributions to the conception or design of the work; or the acquisition, analysis, or interpretation of data for the work; final approval of the version to be published

VG Substantial contributions to the conception or design of the work; or the acquisition, analysis, or interpretation of data for the work; final approval of the version to be published

MG Substantial contributions to the conception or design of the work; or the acquisition, analysis, or interpretation of data for the work; drafting the work or revising it critically for important intellectual content; final approval of the version to be published

\section{REFERENCES}

1. Murphy GJ, Pike K, Rogers CA, Wordsworth S, Stokes EA, Angelini GD, et al. Liberal or restrictive transfusion after cardiac surgery. N Engl J Med. 2015;372(11):997-1008.

2. Tanaka A, Ota T, Uriel N, Asfaw Z, Onsager D, Lonchyna VA, et al. Cardiovascular surgery in Jehovah's Witness patients: the role of preoperative optimization. JThorac Cardiovasc Surg. 2015;150(4):976-83.

3. McCartney S, Guinn N, Roberson R, Broomer B, White W, Hill S. Jehovah's Witnesses and cardiac surgery: a single institution's experience. Transfusion. 2014;54(10 Pt 2):2745-52.

4. Vaislic CD, Dalibon N, Ponzio O, Ba M, Jugan E, Lagneau F, et al. Outcomes in cardiac surgery in 500 consecutive Jehovah's Witness patients: 21 year experience. J Cardiothorac Surg. 2012;7:95.

5. Marshall L, Krampl C, Vrtik M, Haluska B, Griffin R, Mundy J, et al. Short term outcomes after cardiac surgery in a Jehovah's Witness population: an institutional experience. Heart Lung Circ. 2012;21(2):101-4.

6. Jassar AS, Ford PA, Haber HL, Isidro A, Swain JD, Bavaria JE, et al. Cardiac surgery in Jehovah's Witness patients: ten-year experience. Ann Thorac Surg. 2012;93(1):19-25.

7. Marinakis S, Van der Linden P, Tortora R, Massaut J, Pierrakos C, Wauthy P. Outcomes from cardiac surgery in Jehovah's witness patients: experience over twenty-one years. J Cardiothorac Surg. 2016;1 1(1):67. 
8. Stamou SC, White T, Barnett S, Boyce SW, Corso PJ, Lefrak EA. Comparisons of cardiac surgery outcomes in Jehovah's versus NonJehovah's Witnesses. Am J Cardiol. 2006;98(9):1223-5.

9. Bhaskar B, Jack RK, Mullany D, Fraser J. Comparison of outcome in Jehovah's Witness patients in cardiac surgery: an Australian experience. Heart Lung Circ. 2010;19(11):655-9.

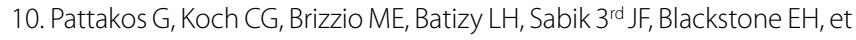
al. Outcome of patients who refuse transfusion after cardiac surgery: a natural experiment with severe blood conservation. Arch Intern Med. 2012;172(15):1154-60.

11. Censo Demográfico 2010: Características gerais da população, religião e pessoas com deficiência [Internet]. Rio de Janeiro: Instituto Brasileiro de Geografia e Estatística - IBGE; 2012. [cited 2016 Nov 6]. Available from: http://www.ibge.gov.br/.

12. Nashef SA, Roques F, Sharples LD, Nilsson J, Smith C, Goldstone AR, et al. EuroSCORE II. Eur J Cardiothorac Surg. 2012;41 (4):734-45. 